\title{
Surgery for recurrent lower lip carcinoma
}

Maharjan $\mathbf{S}^{1}$, Bista $\mathbf{M}^{2}$, Toran $\mathrm{KC}^{3}$, Joshi $\mathbf{K D}^{4}$

${ }^{1}$ Medical Officer, Department of Surgery (Plastic Surgery), ${ }^{2}$ Assistant Professor, Department of ENT, ${ }^{3}$ Associate Professor, Department of ENT, ${ }^{4}$ Professor, Department of Surgery (Plastic Surgery), Kathmandu Medical College, Sinamangal, Nepal

\begin{abstract}
A 38 year old gentleman presented with recurrent Squamos cell carcinoma of lower lip. He had earlier undergone previous surgeries and radiotherapy. At the time that he presented in KMCTH his lower lip area was much scarred and the tongue was shrunk and unavailable for vermilion reconstruction.

This case report is an account of the various treatment carried out to reconstruct the lip. It was done with co-operation of the ENT department.
\end{abstract}

Key words: Recurrent squamous cell carcinoma, Gillies fan flap, Deltopectoral flap, Delay of flaps

\begin{abstract}
Qquamous cell carcinoma of lower lip is not uncommon. This patient does not give any history of smoking or chewing 'pan', 'supari' in excess. His surgery was made more difficult by the presence of scarring from previous surgery and radiotherapy. Nevertheless, local flaps were used to reconstruct the lip as the blood supply in the face is very rich. When recurrence occurred, the Deltopectoral flap was used as cover after delaying it.
\end{abstract}

\section{Case report}

A 38 year old gentleman a known case of lower lip squamous cell carcinoma presented with recurrence.

On examination there was scarring of the lower lip and ulcerations at both commissures, part of the mandible seem to be involved and the left cheek previously operated also seemed to be involved.

Biopsy from the lower lip showed well differentiated squamous cell carcinoma. Biopsy from tongue was negative and from left cheek showed mild dysplasia. CT scan report showed moderately enhancing soft tissue bulge in lower lip on left side with loss of adjacent sub cutaneous fat plane suggestive of recurrence of previous tumour. Mandible was not involved.

\section{Past history}

Four years back he had developed ulcer of the lower lip and biopsy was found to be verrucous carcinoma and subsequently had undergone lower lip shaving. One and half years later wedge excision was done from the lower lip with suspicion of recurrent verrucous carcinoma and the report came out to be well differentiated squamous cell carcinoma. He received radiotherapy for the recurrence. A year later left buccal mucosa biopsy showed well differentiated squamous cell carcinoma and wide excision and buccal mucosal flap was done and biopsy report was squamous cell carcinoma well differentiated infiltrating into underlying muscles without invasion of lympho-vascular structures. Resected margins were free of tumour. For any residual disease he was referred for radiotherapy.

Joint team of ENT department and Plastic Surgery unit of KMC decided to do wide excision of lower lip along with previously involved left cheek with suspicious mandibular area.

Thus, wide excision of lower lip with part of left cheek and left commissure with mandibulectomy was done. Lower lip reconstruction was undertaken with Gillies ${ }^{1}$ bilateral fan flaps.

Patient was then transferred to intensive care unit (ICU) and he was started on (nasogastric) NG feed after 48 hours of surgery. As anticipated the central area of flaps was under tension and it necrosed. On third post operative day patient was again taken to operation theatre and release of tension by Webster ${ }^{2}$ flap on right

Correspondence

Dr. Suraj Maharjan

House Officer, Dept of Surgery (Plastic Surgery)

Kathmandu Medical College Teaching Hospital

Sinamangal, Kathmandu

E-mail: surazonline@hotmail.com 
side. The result after second operation was good. On 11th post operative day all sutures were removed and patient was discharged.

After 3 months he again presented with tight commissure and a left submandibular immobile hard node of which FNAC showed recurrent squamous cell carcinoma. Computed tomography (CT) scan neck done to see any spread. ENT surgeons decided to go for Modified Radical Neck dissection and we decided to do Deltopectoral flap ${ }^{3,4,5}$ reconstruction of lower lip and chin.

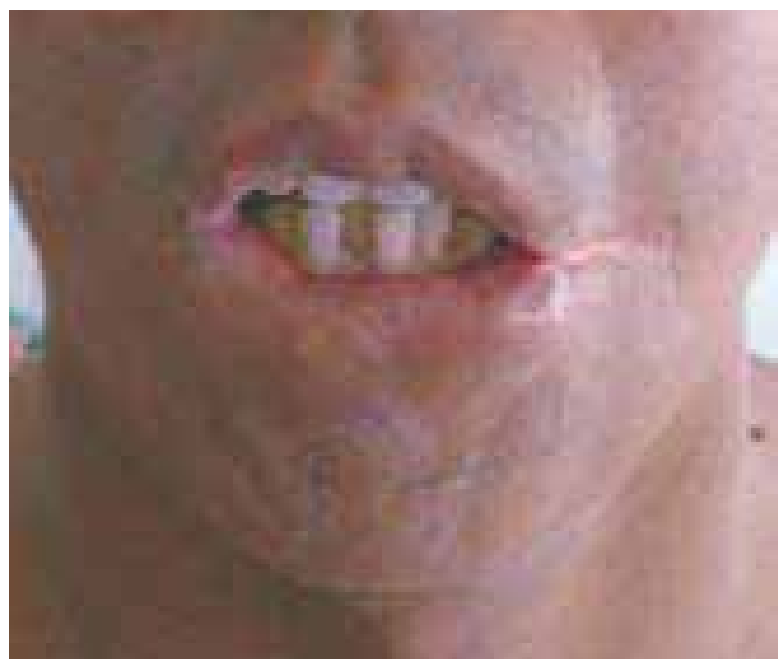

Fig 1: On presentation

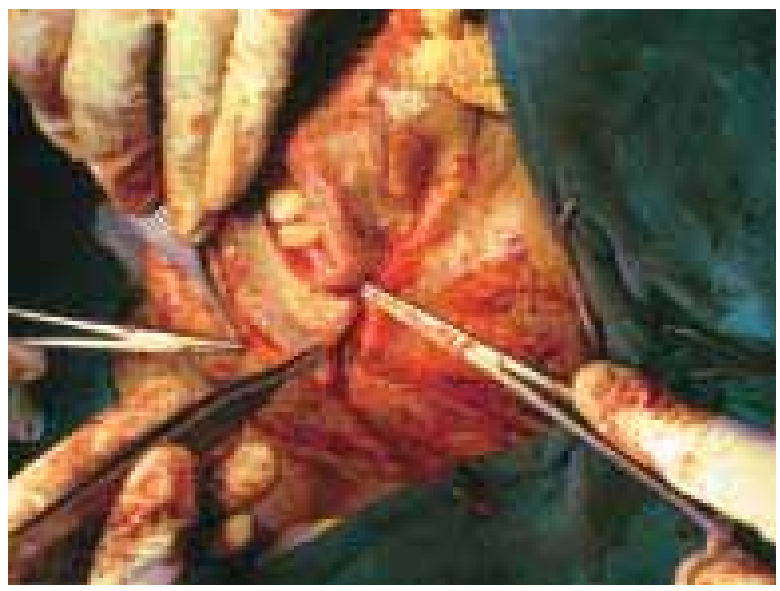

Fig 3: Gillies bilateral Fan flap reconstruction
Following operations were carried out:

- First surgery: Delaying of Deltopectoral flap

- Two weeks later second surgery was done: Modified Radical Neck dissection along with Deltopectoral pedicle flap for lower lip and chin reconstruction.

- Three weeks later third surgery: D-P Pedicle flap returned to chest with SSG to deltoid area.

Patient had to stay for dressings due to graft site infection otherwise post operative period were uneventful. He was discharged after a month of third surgery with satisfying result.

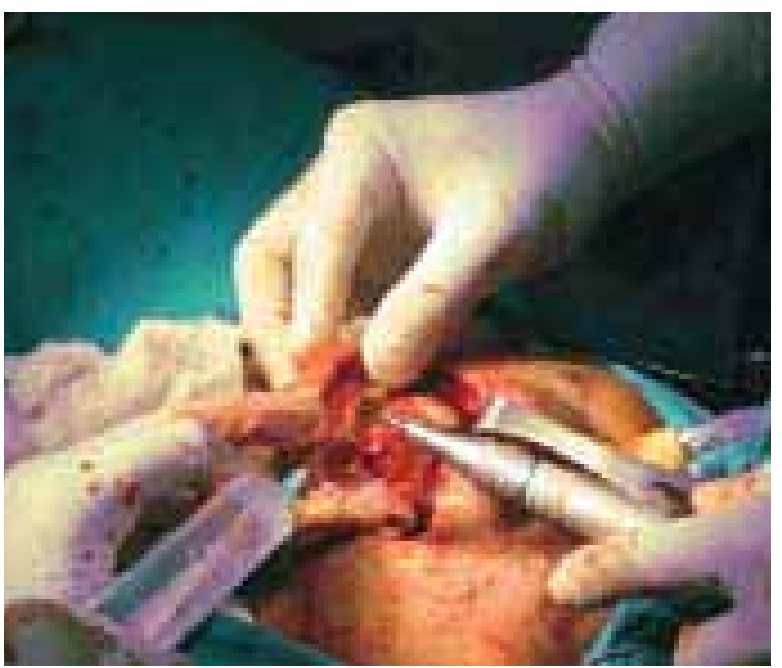

Fig 2: Mandible being excised

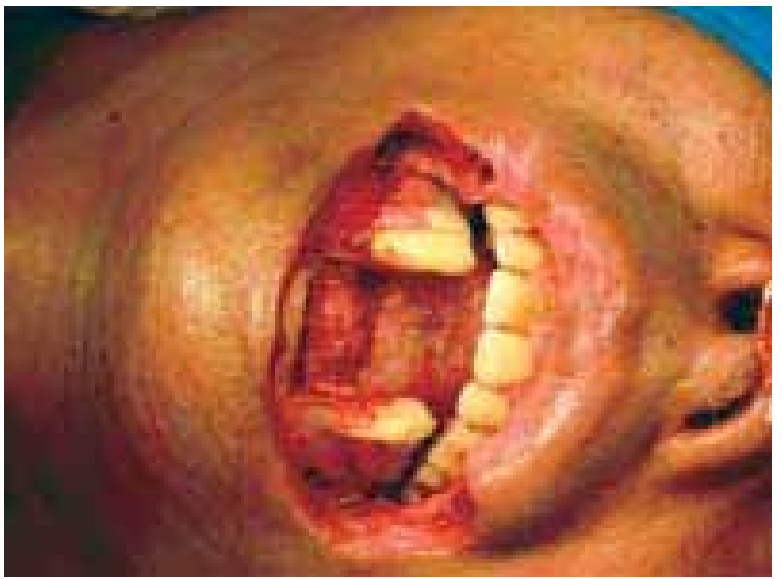

Fig 4: After mandibulectomy 


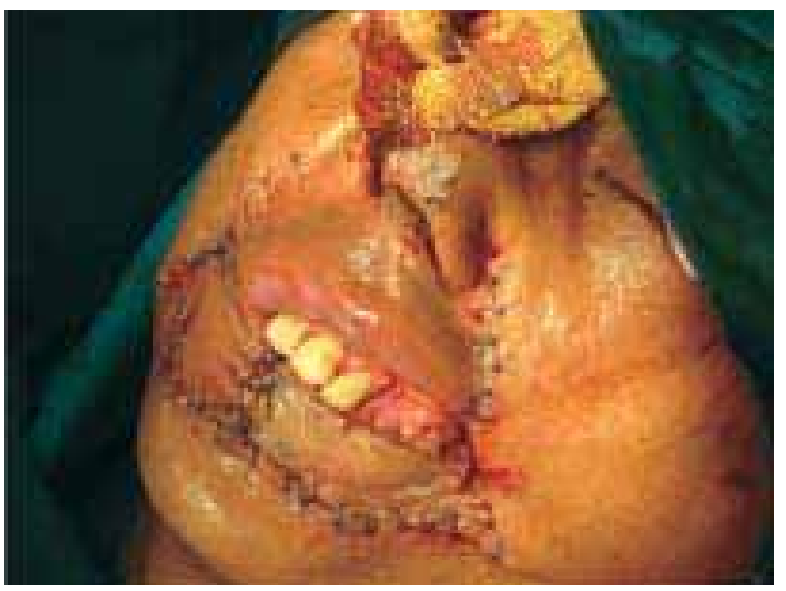

Fig 5: After Gillies fan flap reconstruction

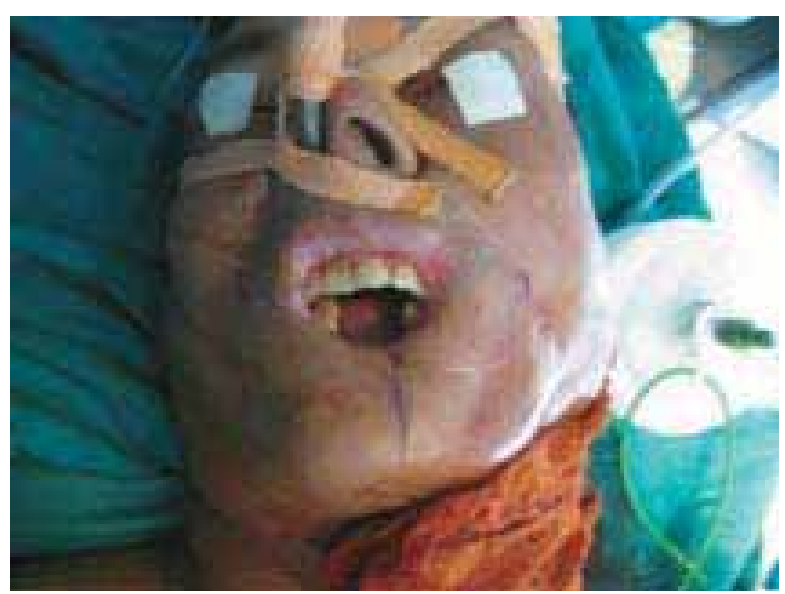

Fig 7: Before Deltopectoral flap

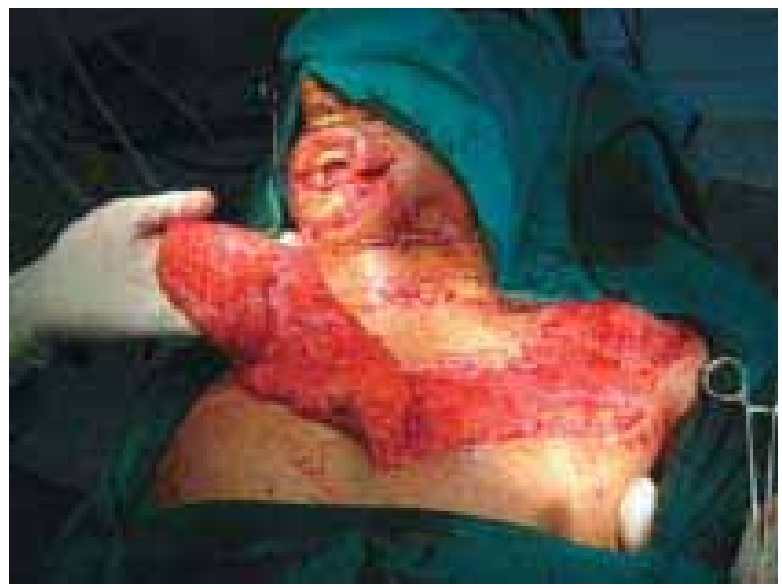

Fig 9: Delto pectoral flap

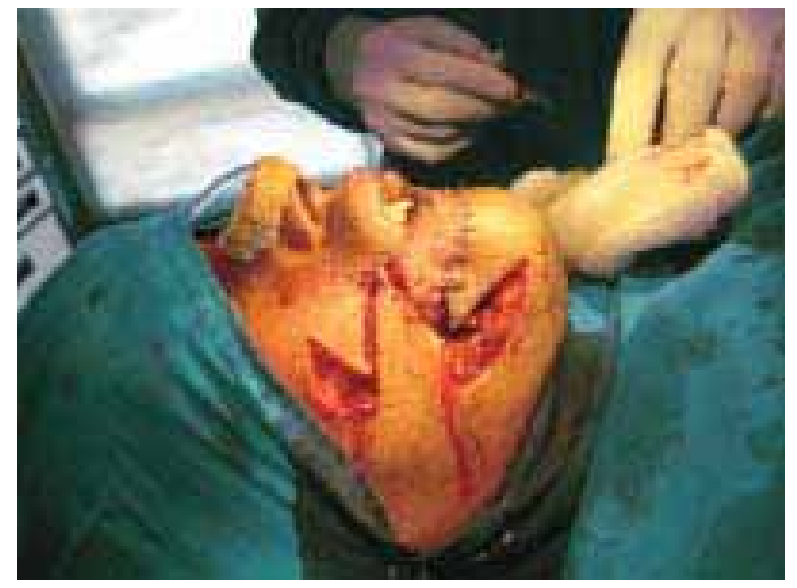

Fig 6: Webster flap

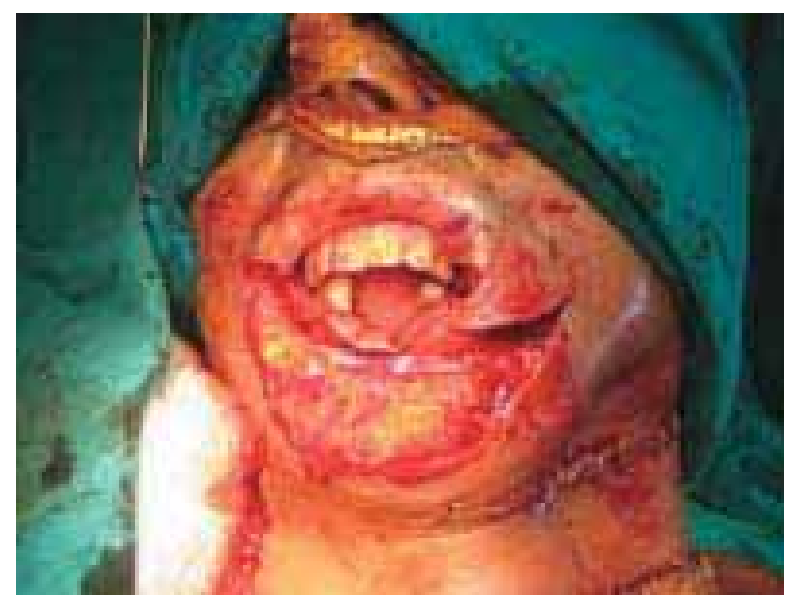

Fig 8: After Neck dissection and wide excision

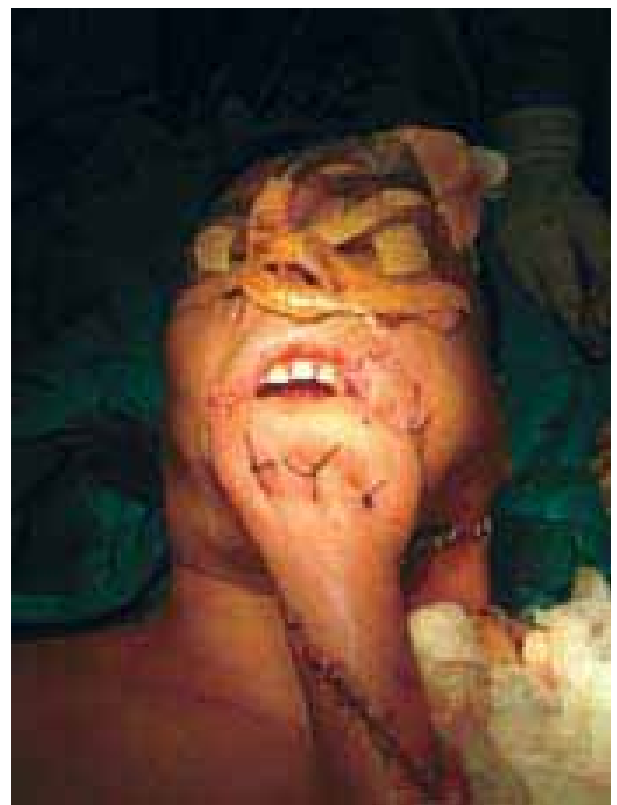

Fig 10:Delto pectoralflap in place 


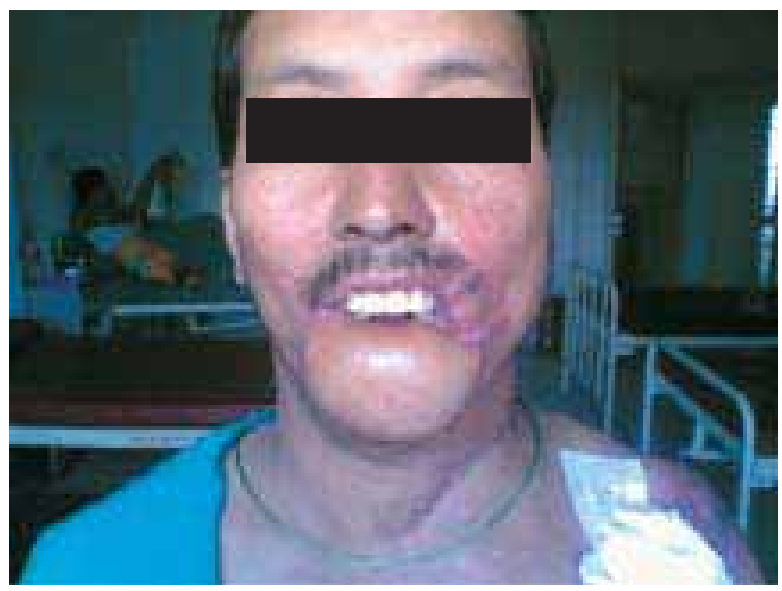

Fig 11: One month after discharge

\section{Discussion}

Of all the skin carcinomas, Squamous Cell Carcinoma is one of the common ones after Basal Cell Carcinoma. The lip is a common site. Due to lack of facilities of microsurgery, the reconstruction has become a step by step procedure in our institute. Another disadvantage is the lack of frozen section, so we never know if we have a clear margin. Nevertheless, the challenge is worth accepting as we want to give the patient a better quality of life.

\section{Acknowledgement}

We would like to thank the Department of ENT (Dr. Toran K.C and team) and Anaesthesia Department for the co-operation and help, which made the surgery so much easier for the patient.

\section{References}

1. Frowde H, Hodder and Stoughton Gillies HD Plastic surgery of the face. London: Henry Frowde Oxford University Press, Hodder \& Stoughton, 1920.

2. Webster RC, Coffey RJ, Kelleher RE. Total and partial reconstruction of the lower lip with innervated muscle-bearing flaps. Plast Reconstr Surg 1960;25:360-70.

3. Grabb WX, Smith JW. Plastic Surgery. 3rd ed. Boston: Lippincott Williams \& Wilkins; 2006.

4. Bakamijam,VY. A two-stage method for pharyngoesophageal reconstruction with a primary pectoral skin flap. Plast Reconstr Surg. 1965;36:173.

5. Lore JM. General purpose flaps. In: Lore JM, editor. An Atlas of Head and Neck Surgery. $3^{\text {rd }}$ ed. Philadelphia, PA: WB Saunders Co; 1988:344-57. 